\title{
Diagnosis and management of ventricular dysphonia
}

\author{
CHRISTOPHER P. VON HAKE, DO \\ ILENE P. GANZMAN, MS \\ THEODORE P. MAUER, DO
}

\begin{abstract}
Ventricular phonation may develop on a functional level, or it may occur as an alternative voice for the patient who has an organic disease of the true vocal folds. Three cases that represent iatrogenic, traumatic, and neurologic forms of the disorder are reported. Diagnosis, treatment, and guidelines for follow-up speech therapy are discussed.
\end{abstract}

Ventricular dysphonia, which also is known as dysphonia plicae ventricularis, is a laryngeal phenomenon that has received little attention in the medical literature. It is caused by the participation of the false vocal cords, or ventricles, in phonation. The disorder is considered to be a rare type of dysphonia; based upon clinical reports, it occurs in approximately $1 \%$ of the general population. ${ }^{1}$

According to Arnold and Pinto ${ }^{2}$ after the invention of the laryngeal mirror in 1854, Czermak made the first report of ventricular dysphonia in 1860 . Merkel presented clear illustrations demonstrating hyperkinesis of the ventricular folds in $1862 .{ }^{2}$ In 1893 , Schmidt described faulty phonation with ventricular folds. ${ }^{2}$ Flatau and Gutzmann addressed the ventricular folds in a textbook on ventriloquism in 1894, and, in 1928, Flatau discussed the therapy of ventricular dysphonia. ${ }^{2}$

The vocal quality has been described as strained or strangulated, and the dysfunction often can be confused with hoarseness or vocal fry. The low pitch, monotony, rumbling, and cracking or rattling characteristics make most ventricular voices sound unpleasant. ${ }^{3}$ Because of the simultaneous participation of the false and true vocal cords, some patients exhibit diplophonia (double voice).

The etiology is unclear, but ventricular dysphonia is known to occur spontaneously in response to laryngeal insult.
When it is functionally based, it can occur in muscularly tense people and can be considered to be a musculoskeletal tension disorder. ${ }^{4}$

Diagnosis on the basis of a voice examination alone is difficult. During direct or indirect laryngoscopy, the ventricular folds are noted to adduct together over the true cords and to obliterate examination of the true cords. Hypertrophy of the ventricular bands often is an associated finding.

Three cases that represent iatrogenic, traumatic, or neurologic etiologies of ventricular dysphonia are presented.

\section{Report of cases \\ Case 1}

A 24-year-old man with a longstanding history of hoarseness had had laryngeal polyposis as a child and had undergone multiple vocal cord strippings. The patient was extremely breathy and reported an inability to mount an adequate Valsalva maneuver during physical exertion. He denied any significant history of aspiration, however.

During flexible indirect laryngoscopy, the false cords were noted to be hypertrophied and mobile; there was approximately $75 \%$ glottic closure. A large defect, which contributed to a large glottic chink, was seen in the posteromedial aspect of the left true vocal cord.

The patient underwent vocal cord augmentation with teflon paste, which was injected into the body of the left vocalis musculis. The procedure was performed under local anesthesia, so that the patient could phonate during it.

The distal end of the laryngoscope was at the level of the laryngeal ventricle, which maintained the false cords in an abducted state. The paste corrected the defect, and the vocal quality was clear and amplified.

On removal of the laryngoscope, the false cords again were mobile, and the vocal quality deteriorated. The voice was harsh and deep, but not breathy. The laryngoscope was reinserted below the false cords and the voice improved dramatically. The patient was referred for postoperative speech therapy. 
Case 2

A 36-year-old man had sustained laryngeal trauma and fracture from the blow of a horse's hoof at the age of 18. Tracheostomy was performed and maintained for several months. The patient refused laryngeal reconstruction or placement of a stent. He also refused post-trauma speech therapy, and his vocal quality was harsh and raspy, with evidence of diplophonia. The hoarseness had been stable over the years.

Flexible indirect laryngoscopy revealed a shift of the false cords to the left. The chink between the false cords was positioned over the left true vocalis musculis. The mobility of the arytenoids and true vocal cords was normal, with adequate glottic closure and Valsalva maneuver. The superior laryngeal nerve function was intact. The false cords were noted to be hypertrophied and somewhat mobile with phonation. The patient denied stridor, aspiration, or dysphagia.

\section{Case 3}

Approximately 18 years prior to the current evaluation, a 60-year-old woman developed spontaneous, bilateral abductor paralysis. To improve her airway, she underwent Woodman arytenoid lateralization of the left vocal cord. At that time, she had a persistent, slight breathiness of the voice.

Several years later, she developed idiopathic adductor paralysis of the right true vocal cord. The right cord was maintained in a cadaveric position, and the patient's breathiness increased. She never had follow-up speech therapy to improve adduction of the right true vocal cord. During the next 15 years, she spontaneously developed ventricular phonation to overcome the deficit.

At flexible indirect laryngoscopy during the present examination, the false vocal cords were noted to be hypertrophied and underwent abduction and adduction with phonation. The patient was able to protect the airway from aspiration with closure of the false vocal cords.

\section{Discussion}

According to Arnold and Pinto, ${ }^{2}$ there are six specific forms of the disorder-habitual, emotional, paralytic, cerebral, cerebellar, and compensatory, which acts as a substitute voice for the defective true vocal folds.

The habitual form of this type of dysphonia may be caused by vocal abuse. The individual may engage constantly in vocally abusive activities, including shouting, screaming, and excessive talking.

Ventricular phonation also may result from an emotional crisis. After increased observations of the phenomenon during World Wars I and II, various laryngologists considered a type of conversion reaction to be an etiology. ${ }^{2}$ Arnold and Pinto ${ }^{2}$ also report that psychotherapy may be indicated for the patient who exhibits emotional ventricular phonation. Adjunctive treatments may include biofeedback, relaxation therapy, and antianxiety agents.
The vocal deficit may develop as a result of laryngeal paralysis or as a form of dysarthria secondary to cerebral disease. In these cases, the voice is low, rough, and spastic. It also has been an associated finding in cerebellar lesions or midbrain disease (for example, parkinsonism). ${ }^{2}$

Ventricular phonation can occur as a substitute for the failing or defective voice. The individual often attempts to compensate and to produce a stronger voice. If an abnormally low pitch level is used and too much laryngopharyngeal resonance is produced, the patient may develop ventricular phonation secondary to vocal hyperfunction. ${ }^{1}$

Appropriate management of ventricular dysphonia is contingent upon clinical judgment (Fig 1 ), and referral for vocal rehabilitation is dependent upon numerous variable factors. The aim of voice therapy is to help the patient establish a more normal voice. Patient motivation is crucial and must be considered before the initiation of services.

Voice therapy can be very useful when the patient has the laryngeal capabilities to produce true cord phonation. However, any physical impairment of the true vocal fold that makes normal phonation impossible must be identified. ${ }^{3}$

Arnold and Pinto ${ }^{2}$ report that local laryngeal procedures (for example, separating the ventricular cords following local anesthesia) allow for better vibration of the vocal folds and may promote true cord phonation. This phenomenon was illustrated clearly in case 1 . Surgical procedures would be recommended to debulk the hypertrophic portion of the ventricular folds only after an extensive trial of speech therapy. ${ }^{2,5}$ The carbon dioxide laser has been used successfully to debulk the hypertrophied false vocal cords. ${ }^{6}$

The prognosis for re-establishing true vocal cord fold phonation via therapeutic intervention has been reported ${ }^{1,7}$ to vary from guarded to good, dependent upon the length of time that the dysphonia has been present and the patient's level of motivation. The patient in case 3 developed ventricular phonation as a substitute voice to compensate for an inability to produce true cord phonation. For this particular patient, intervention to improve the vocal characteristics of the patient's ventricular phonation (pitch and loudness) could be attempted.

\section{Summary}

The definition, etiologies, diagnosis, and therapeutic considerations for ventricular dysphonia have been presented. Three cases with different etiologic factors have been described. The speech examination must be supplemented by indirect or direct laryngoscopy, and the flexible nasopharyngolaryn- 
Patient presents to office with hoarseness of longer than three weeks' duration:

Obtain medical history detailing smoking history, dysphagia, weight loss, neck pain, adenopathy, allergy, referred otalgia, hemoptysis, previous radiation exposure to neck, stress, and previous neck surgery.

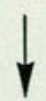

Perform medical examination, as follows: Study vocal characteristics, including pitch, loudness, and quality; palpate neck, larynx, and trachea; and examine oropharynx, hypopharynx, laryngopharynx, and larynx using either a no. 4 or no. 5 indirect mirror, a rigid fiberoptic or Hopkins rodlens system, or, preferably, a flexible fiberoptic nasopharyngolaryngoscope.

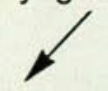

True vocal cord, false vocal cord, subglottis, or epiglottis pathologic findings

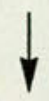

Further work-up and biopsy via direct operative laryngoscopy

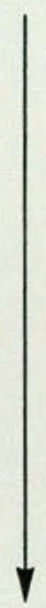

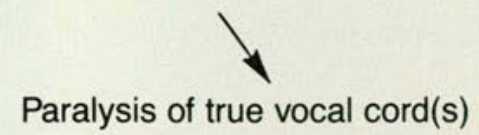

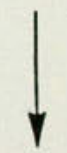

Further work-up, including neurologic examination and chest roentgenography<smiles>[CH][AlH2]</smiles>

Speech and voice evaluation

Normal functioning true vocal cords obliterated by hyperkinetic or hypertrophied false vocal cords<smiles>C[13CH]</smiles>

Diagnosis of ventricular dysphonia<smiles>C[13CH]</smiles>

Speech therapy

Fig 1. Management scheme for ventricular dysphonia.

goscope has facilitated greatly the examination of the patient with any form of dysphonia. The rationale for vocal rehabilitation is discussed. Therapeutic recommendations must be considered on an individual basis.

1. Cooper M: Modern Techniques of Vocal Rehabilitation. Springfield, IIl, Charles C Thomas, 1973.

2. Arnold GE, Pinto S: Ventricular dysphonia: New interpretation of an old observation. Laryngoscope 1960;70:1608-1627.

3. Boone D: The Voice and Voice Therapy. Englewood Cliffs, NJ; PrenticeHall, 1977.
4. Aronson A: Clinical Voice Disorders. New York; Thieme Inc, 1985. 5. Jackson C, Jackson CL: Dysphonia plicae ventricularis. Arch Otolaryngol 1935;21:157-167.

6. Karlan MS, Ossoff RH: Laser surgery for benign laryngeal disease. Surg Clin N Am 64:1984;988.

7. Prater R, Swift R: Manual of Voice Therapy. Boston and Toronto, Little, Brown and Co, 1984.

From the Department of Otorhinolaryngology and Head and Neck Surgery, Osteopathic Medical Center of Philadelphia.

Reprint requests to Von Hake, DO, Suite H, 616 S 13th St, Pekin IL 61554. 


\section{THE SHAPE OF THINGS TO COME FOR MILLIONS OF WOMEN}

\section{IF OSTEOPOROSIS ISN'T TREATED}

The National Osteoporosis Foundation (NOF) has the resources you need to help you reshape the future in the prevention and treatment of osteoporosis.

But we need you, too. We need your support to help fund the urgently needed research and educational effort that can conquer a crippling disorder affecting 24 million Americans and resulting in 1.3 million bone fractures annually, including 500,000 vertebral fractures.

For more information about NOF, please mail the coupon at the bottom of this ad. We'll send you materials that describe our goals and achievements; a listing of available literature (including our widely-acclaimed Physicians Resource Manual), and information about our tax-deductible membership fees.

THE ONLY NATIONAL VOLUNTARY HEALTH ORGANIZATION DEDICATED TO OSTEOPOROSIS.
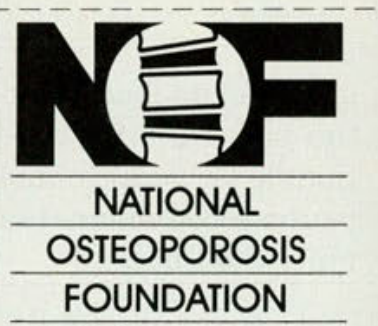

1625 EYE STREET, N.W. SUITE 822 WASHINGTON, D.C. 20006 (202) 223.2226

Please send me the NOF information package.

\section{(1)}

Name

Address 